\title{
Occurrence of Euryhaline Dunaliella salina in Andaman \& Nicobar Islands: Assessment and Optimization of its Total Carotenoid by Orthogonal Array Design
}

\author{
Jayappriyan Kothilmozhian Ranishree ${ }^{1,2 *}$, Sathish Tadikamalla², Baskar \\ Balakrishnan ${ }^{2,3}$, Dheenan Palaiya Sukumaran², Vinithkumar Nambali Valsalan², \\ Dharani Gopal ${ }^{4}$ and Kirubagaran Ramalingam ${ }^{4}$
}

${ }^{1}$ Centre for Advanced Studies in Botany, University of Madras, Guindy Campus, Chennai - 600025 , India. ${ }^{2}$ Andaman and Nicobar Centre for Ocean Science and Technology, Earth System Sciences Organization - National Institute of Ocean Technology, Dollygunj, Port Blair, Andaman and Nicobar Islands - 744 103, India. ${ }^{3}$ Department of Immunology, Mayo Clinic, Rochester, Minnesota 55905, USA. ${ }^{4}$ Earth System Sciences Organization - National Institute of Ocean Technology, Ministry of Earth Sciences, Government of India, Pallikaranai, Chennai - 600 100, Tamil Nadu, India.

\begin{abstract}
Dunaliella salina has been widely reported in the halophilic environment. The present study first time reveals and reports the presence of green alga $D$. salina identified by both morphological and molecular identification from Andaman and Nicobar Islands, a rainy tropical environment. Besides, it was adapted for the optimization of total carotenoid production by using Taguchi tool with various combinations of different parameters, like light intensity, pH, salinity, $\mathrm{NaNO}_{3}$ and $\mathrm{NaH}_{2} \mathrm{PO}_{4}$ in basal De Walne's medium of which $40 \mu \mathrm{Em}^{-2} \mathrm{~s}^{-1}$ light intensity showed maximum production of $249.24 \mu \mathrm{g} / \mathrm{mL}$ of total carotenoid followed by $\mathrm{NaNO}_{3}, \mathrm{NaH}_{2} \mathrm{PO}_{4}, \mathrm{pH}$, and salinity. Hence, this study proves that $D$. salina possesses the character of adapting to the extreme habitats with total carotenoid production.
\end{abstract}

Keywords: Dunaliella salina; marine algae; halophilic; $\beta$-carotene; Taguchi.

\footnotetext{
*Correspondence: jayapriyan@gmail.com

(Received: 02 August 2019; accepted: 09 September 2019)

Citation: Jayappriyan Kothilmozhian Ranishree, Sathish Tadikamalla, Baskar Balakrishnan, DheenanPalaiya Sukumaran, Vinithkumar Nambali Valsalan, Dharani Gopal and Kirubagaran Ramalingam, Occurrence of Euryhaline Dunaliella salina in Andaman \& Nicobar Islands: Assessment and Optimization of its Total Carotenoid by Orthogonal Array Design, J Pure Appl Microbiol., 2019; 13(3): 1363-1374. https://doi.org/10.22207/JPAM.13.3.07

C The Author(s) 2019. Open Access. This article is distributed under the terms of the Creative Commons Attribution 4.0 International License which permits unrestricted use, sharing, distribution, and reproduction in any medium, provided you give appropriate credit to the original author(s) and the source, provide a link to the Creative Commons license, and indicate if changes were made.
} 


\section{INTRODUCTION}

The marine ecosystem is an immense source of potential microorganisms and compounds that holds a wide range of biotechnological applications ${ }^{1-3}$. In earlier decades scientific community had shown considerable interest on taxonomy, physiology, and metabolism of microalgae. Hence, this paved a way to identify the various potential resources from microalgae. In a present scenario, utilization of microalgae are sprouted more in various industries, such as food, feed, fine chemicals, energy, etc. due to its photosynthetic traits, generation time, the presence of high-value compounds, capability in controlling pollution, etc. Dunaliella is unicellular, biflagellate, naked, motile green alga belongs to the family Polyblepharidaceae inhabits the marine environment and commonly seen in hypersaline environments ${ }^{4,5}$. This is originally first described and reported from the occurrence in saltern brines by Dunal ${ }^{6}$ and later discovered by Teodoresco in $1905^{7}$. Dunaliella varies in morphology and it is well known to show polymorphic character since it lacks cell wall. There is also a need for molecular characterization and to examine the level of carotenoid accumulation, especially under different conditions of growth. Dunaliella salina is reported to yield $\sim 400 \mathrm{mg}$ $\beta$-carotene $/ \mathrm{m}^{2}$ of cultivation area under ideal conditions $^{8}$. Dunaliella salina is the richest source of carotenoid, $\beta$-carotene ${ }^{6}$. Dunaliella salina can accumulate $\beta$-carotene more than $14 \%$ of its dry weight besides producing other carotenoids, like $\alpha$-carotene and xanthophylls like zeaxanthin, cryptoxanthin and lutein ${ }^{9,10}$. Natural $\lambda$-carotene has high antioxidant, anti-cancer and immune regulations properties when compared to synthetic $\lambda$-carotene and it is now produced from Dunaliella on a commercial scale in Australia, USA, Israel, China, Chile, Spain, Kuwait and India.

Andaman and Nicobar Islands (A \& N) is located in the eastern part of Bay of Bengal, encompasses 572 islands and are heavily inhabited by rich floral communities ranging from small microalgae to highly evolved floral organisms. A $\& \mathrm{~N}$ has a moderate climate with a temperature ranges from 23 to $31^{\circ} \mathrm{C}$ but with relatively high humidity (70 to $90 \%$ ) coupled with heavy rainfall approximately more than $318 \mathrm{~cm} /$ year (http:// www.imd.gov.in/pages/main.php). A \& N island holds $40 \%$ of coral reef coverage of entire Indian coastline, provides shelter for diverse marine creatures ${ }^{11}$. The present study aims at the quantification and optimization of carotenoid production in the marine microalgae $D$. salina by Taguchi statistical tool for enhancing the total carotenoids production after identification by $18 \mathrm{~S}$ rDNA sequencing.

\section{MATERIALS AND METHODS}

\section{The collection, Purification, and Isolation}

Five hundred liters of seawater collected from Minnie Bay (Latitude $11^{\circ} 38^{\prime} 39.50^{\prime \prime} \mathrm{N}$ Longitude $\left.92^{\circ} 42^{\prime} 28.15^{\prime \prime} \mathrm{E}\right)$, A\&N Islands, India were filtered in $20 \mu \mathrm{m}$ plankton net. The soup was kept for enrichment in $250 \mathrm{~mL}$ Erlenmeyer flask containing $100 \mathrm{~mL}$ De Walne's medium initially for 5 days. After incubation, $0.1 \mathrm{~mL}$ from initial enrichment was inoculated in $5 \mathrm{~mL}$ test tubes containing $1 \mathrm{~mL}$ De Walne's medium ${ }^{12}$ for 30 days to isolate a Dunaliella sp. Above procedure was repeatedly carried out in triplicates for subsequent times to facilitate isolation of Dunaliella species in seawater. Mixed culture was periodically checked for Dunaliella under microscope, while the diatoms existed in enrichment samples were removed by modified method ${ }^{13}$ using Germanium dioxide $\left(\mathrm{GeO}_{2}\right)$ at a different concentration from 5 to $25 \mu \mathrm{g} / \mathrm{L}$. Enrichment sample were diluted up to $1^{\prime} 10^{-6}$ dilution and $0.1 \mathrm{~mL}$ was spread on $2 \%$ De Walne's agar medium. Distinct colonies developed on the plates were made axenic by triple antibiotic treatment ${ }^{14}$ and transferred to De Walne's medium and incubated at $24 \pm 1^{\circ} \mathrm{C}$ in a thermostatically controlled area, illuminated through cool fluorescent lamps at irradiance of 30 $\mu \mathrm{Em}^{-1} \mathrm{~s}^{-1}$, under $12 \mathrm{~h}$ light $/ 12 \mathrm{~h}$ dark photoperiod ${ }^{1}$. Identification

Identification of the isolated microalga was done by microscopic observations, such as cell size, shape, colour, cell length (L), width (W), flagella length (F) chloroplast arrangement and growth characteristics (the measurements of length and breadth of the cells were calculated from mean value of 100 cells). Besides, it was also identified using $18 \mathrm{~S}$ rDNA sequence in order to avoid the ambiguity in identification. Amplification of the $18 \mathrm{~S}$ rDNA and sequencing PCR amplification was performed on cells taken directly from plates. For PCR, the genomic DNA of the Dunaliella sp. was 
isolated according to Sambrook et al. ${ }^{15}$, subjected to amplification with the universal eukaryotic forward primers (5'GTCAGAGGTGAAATTGGATTTA'3) and reverse primer (5'AGGGCAGGGACGTAATCAACG'3) performed as described by Rasoul-Amini et al. ${ }^{16}$. The amplified product partially sequenced (Applied Bio System Instrument (ABI) Prism 310 Genetic) and resulted sequence was submitted to GenBank, NCBI with the accession number (KP635215).

\section{Growth and Screening of Total carotenoids}

The isolated Dunaliella salina was studied for its growth and total carotenoids production under laboratory conditions. Initially, $10 \mathrm{~mL}$ of log phase culture of Dunaliella isolates were inoculated in $90 \mathrm{~mL}$ of basal medium and kept under $30 \mu \mathrm{Em}^{-2} \mathrm{~s}^{-1}$ light intensity, $12 \mathrm{~h}$ light $/ 12 \mathrm{~h}$ dark cycle and at $24 \pm 1^{\circ} \mathrm{C}$. Samples were collected and analyzed for the following parameters at every 3 day interval for the period of 30 days. i) Cell number $(\mathrm{Cn})$ using haemocytometer (Thoma) $\left(\log _{10}\right.$ cells $\left./ \mathrm{mL}\right)$ and ii) concentrations of pigments viz., Chl a, Chl b and total carotenoid of Dunaliella samples extracted were estimated as per ${ }^{17}$. Also, cell division rates were calculated during the exponential phase as per the method of ${ }^{18}$.

Optimization of the total carotenoid production by Taguchi method

With the aim to improve total carotenoids production by Dunaliella sp. AT-JP-13, five

Table 1. L-32 orthogonal design along with the obtained carotenoids produced by D. salina (AT-JP-13)

\begin{tabular}{|c|c|c|c|c|c|c|c|}
\hline No. & $\begin{array}{c}\text { Light } \\
\text { intensity } \\
\left(\mu \mathrm{E} / \mathrm{m}^{2} / \mathrm{S}\right)\end{array}$ & $\begin{array}{c}\mathrm{NaH}_{2} \mathrm{PO}_{4} \\
\text { concen. } \\
(\mu \mathrm{M})\end{array}$ & $\begin{array}{c}\mathrm{NaCl} \\
\text { concen. } \\
(\mathrm{M})\end{array}$ & $\mathrm{pH}$ & $\begin{array}{c}\mathrm{NaNO}_{3} \\
\text { concen. } \\
(\mu \mathrm{M})\end{array}$ & $\begin{array}{c}\text { Total } \\
\text { carotenoids } \\
(\mu \mathrm{g} / \mathrm{ml})\end{array}$ & $\begin{array}{c}\log _{10} \text { of cell } \\
\text { numbers/ } \\
\mathrm{mL}\end{array}$ \\
\hline 1 & 20.00 & 0.50 & 0.50 & 7.00 & 0.50 & 48.00 & 5.562 \\
\hline 2 & 20.00 & 0.75 & 0.75 & 7.50 & 1.00 & 90.46 & 5.672 \\
\hline 3 & 20.00 & 1.00 & 1.00 & 8.00 & 1.50 & 60.92 & 6.612 \\
\hline 4 & 20.00 & 1.25 & 1.50 & 8.50 & 2.00 & 108.92 & 6.703 \\
\hline 5 & 30.00 & 0.50 & 0.50 & 7.50 & 1.00 & 216.00 & 6.12 \\
\hline 6 & 30.00 & 0.75 & 0.75 & 7.00 & 0.50 & 223.38 & 6.42 \\
\hline 7 & 30.00 & 1.00 & 1.00 & 8.50 & 2.00 & 134.76 & 6.701 \\
\hline 8 & 30.00 & 1.25 & 1.50 & 8.00 & 1.50 & 173.53 & 6.412 \\
\hline 9 & 40.00 & 0.50 & 0.75 & 8.00 & 2.00 & 158.76 & 6.214 \\
\hline 10 & 40.00 & 0.75 & 0.50 & 8.50 & 1.50 & 195.69 & 6.726 \\
\hline 11 & 40.00 & 1.00 & 1.50 & 7.00 & 1.00 & 227.07 & 6.705 \\
\hline 12 & 40.00 & 1.25 & 1.00 & 7.50 & 0.50 & 179.07 & 6.155 \\
\hline 13 & 50.00 & 0.50 & 0.75 & 8.50 & 1.50 & 168.00 & 5.812 \\
\hline 14 & 50.00 & 0.75 & 0.50 & 8.00 & 2.00 & 116.30 & 5.962 \\
\hline 15 & 50.00 & 1.00 & 1.50 & 7.50 & 0.50 & 131.07 & 6.164 \\
\hline 16 & 50.00 & 1.25 & 1.00 & 7.00 & 1.00 & 153.23 & 6.120 \\
\hline 17 & 20.00 & 0.50 & 1.50 & 7.00 & 2.00 & 48.00 & 5.550 \\
\hline 18 & 20.00 & 0.75 & 1.00 & 7.50 & 1.50 & 57.23 & 4.996 \\
\hline 19 & 20.00 & 1.00 & 0.75 & 8.00 & 1.00 & 86.76 & 4.871 \\
\hline 20 & 20.00 & 1.25 & 0.50 & 8.50 & 0.50 & 116.30 & 5.136 \\
\hline 21 & 30.00 & 0.50 & 1.50 & 7.50 & 1.50 & 177.23 & 6.616 \\
\hline 22 & 30.00 & 0.75 & 1.00 & 7.00 & 2.00 & 136.61 & 6.743 \\
\hline 23 & 30.00 & 1.00 & 0.75 & 8.50 & 0.50 & 68.30 & 6.456 \\
\hline 24 & 30.00 & 1.25 & 0.50 & 8.00 & 1.00 & 145.84 & 6.552 \\
\hline 25 & 40.00 & 0.50 & 1.00 & 8.00 & 0.50 & 217.84 & 6.740 \\
\hline 26 & 40.00 & 0.75 & 1.50 & 8.50 & 1.00 & 232.61 & 6.686 \\
\hline 27 & 40.00 & 1.00 & 0.50 & 7.00 & 1.50 & 134.76 & 6.612 \\
\hline 28 & 40.00 & 1.25 & 0.75 & 7.50 & 2.00 & 114.46 & 6.799 \\
\hline 29 & 50.00 & 0.50 & 1.00 & 8.50 & 1.00 & 204.92 & 6.495 \\
\hline 30 & 50.00 & 0.75 & 1.50 & 8.00 & 0.50 & 158.76 & 6.314 \\
\hline 31 & 50.00 & 1.00 & 0.50 & 7.50 & 2.00 & 73.84 & 6.588 \\
\hline 32 & 50.00 & 1.25 & 0.75 & 7.00 & 1.50 & 57.23 & 6.476 \\
\hline
\end{tabular}


decisive parameters in De Walne's basal medium, such as light intensity, medium initial $\mathrm{pH}$ and concentrations of $\mathrm{NaH}_{2} \mathrm{PO}_{4}, \mathrm{NaCl}$ and $\mathrm{NaNO}_{3}$ were optimized using Taguchi optimization method ${ }^{19,20}$. A 32 runs orthogonal array (L32-OA) design was employed to investigate the effect of selected parameters on total carotenoids production. All selected parameters were studied at 4 different levels. In Taguchi's method, quality is measured by the deviation of a characteristic from its target value and a loss function [ $L(y)]$. The loss function was calculated by the Eq (1).

$$
\mathrm{L}(\mathrm{y})=\mathrm{k} *(\mathrm{y}-\mathrm{m})^{2}
$$

Where $k=$ The proportionality constant,

$\mathrm{m}=$ Target value and

$y=$ Experimental value obtained for each trial.

The goal is to accomplish the higher carotenoid production from isolated algae. Such case 'bigger-is-better' was chosen. When the 'bigger-is-better' quality characteristics the loss function can be written as

$$
\mathrm{L}(\mathrm{y})=\mathrm{k} *\left(1 / \mathrm{Y}^{2}\right)
$$

To explore the obtained results, analysis of variance (ANOVA) test was performed. Further conformational experiments were performed in order to validate the optimum conditions.
Qulitek-4 software, Nutek Inc. was used for the designing and analysis of experiments ${ }^{21}$.

\section{RESULTS}

Initial screening studies reveals that most of the sample soup contains diatoms, Chlorella and Tetraselmis species, few of them had a trace amount of biflagellate species. Therefore, whichever the samples having biflagellate were taken for enrichment in De Walne's medium under thermostatically controlled room. In the beginning period of enrichment, medium was mainly dominated by Tetraselmis sp. growth in addition to that of diatoms. Later, it was diminished once it attained $15^{\text {th }}$ day. After 20 days of incubation, the microscopic observation revealed consistent growth of Dunaliella sp. with trace diatoms. Diatoms were effectively removed at $10 \mu \mathrm{g} / \mathrm{L}$ of Germanium dioxide. Further, $10^{-4}$ dilution has shown the maximum of Dunaliella sp. and colonies were well separated in De Walne's agar medium. The colonies were picked and transferred to $1 \mathrm{~mL}$ of basal medium and further scaled up. The unialgal culture was axenized before taking to optimization study. The cultures were made axenic by triple antibiotic treatment as described previously ${ }^{14}$.

Table 2. Interaction influence, ANOVA and optimized conditions for selected factors for carotenoids production by

\begin{tabular}{|c|c|c|c|c|c|c|c|c|}
\hline & & LT & $\mathrm{NaH}_{2} \mathrm{PO}_{4}$ & $\mathrm{NaCl}$ & $\mathrm{pH}$ & $\mathrm{NaNO}_{3}$ & $\begin{array}{c}\text { others/ } \\
\text { Error }\end{array}$ & Total \\
\hline \multicolumn{2}{|c|}{ Interactions LT } & 0 & 12.77 & 12.16 & 2.77 & \multicolumn{2}{|l|}{8.37} & \\
\hline & $\begin{array}{l}\text { LT } \\
\mathrm{NaH} \mathrm{PO}\end{array}$ & 12.77 & 0 & 11.37 & 76.66 & \multicolumn{2}{|l|}{47.53} & \\
\hline & $\mathrm{NaCl}^{2}$ & 12.16 & 11.37 & 0 & 57.55 & \multicolumn{2}{|l|}{45.67} & \\
\hline & $\mathrm{pH}$ & 2.77 & 76.66 & 57.55 & 0 & \multicolumn{2}{|l|}{22.25} & \\
\hline & $\mathrm{NaNO}_{3}$ & 8.37 & 47.53 & 45.67 & 22.25 & \multicolumn{2}{|l|}{0} & \\
\hline \multirow[t]{5}{*}{ ANOVA } & DoF ${ }^{3}$ & 3 & 3 & 3 & 3 & 3 & 16 & 31 \\
\hline & SS & 49450.74 & 8434.556 & 5883.371 & 3234.804 & 14606.38 & -0.001 & 81609.851 \\
\hline & Variance & 16483.58 & 2811.518 & 1961.123 & 1078.268 & 4868.792 & -0.001 & \\
\hline & F-Ratio & 10.44255 & 1.04405 & 1.08002 & 0.91206 & 2.26866 & & \\
\hline & $\begin{array}{l}\text { Percent } \\
\text { contribution }\end{array}$ & 60.594 & 10.335 & 7.209 & 3.963 & 17.897 & 0.002 & 100 \\
\hline Optimum & Level & 3 & 1 & 4 & 3 & 2 & & \\
\hline conditions & Level Description & 40 & 0.5 & 1.5 & 8 & 1 & & \\
\hline & Contribution & 44.537 & 16.848 & 19.153 & 1.843 & 31.615 & 0 & 113.996 \\
\hline & Total contribution & from all fa & tors 113.99 & & & & & \\
\hline & Current grand ave & erage of per & ormance 13 & 7.995 & & & & \\
\hline & Expected Results & at optimur & ondition 2 & 1.991 & & & & \\
\hline
\end{tabular}
isolated algae (DoF = Degree of freedom; SS = sum of squares) 
The isolated cells from the pure culture of Dunaliella sp. were naked, oblong, with two smooth equal long flagella inserted apically; chloroplast shifted towards the basal region, cells with tapering apical region; cell measuring average of $9.85 \pm 0.59$ (9.5 to $12.0 \mu \mathrm{m})$ long and $8.19 \pm 0.74$ ( 7.0 to $9.5 \mu \mathrm{m}$ ) wide respectively (Fig.1). Whereas, flagella length measuring average of $12.86 \pm 0.64$ (12.0 to $14.0 \mu \mathrm{m}$ ) (Fig.1). The organism showed a maximum growth rate of $6.298 \log _{10}$ cells $/ \mathrm{mL}$ on $21^{\text {st }}$ day and the division rate was 1.008 per day (Fig. 2). Maximum concentrations of $\mathrm{Chl}-\mathrm{a}, \mathrm{Chl}-\mathrm{b}$, and total carotenoids were $4.42,2.24$ and $6.17 \mu \mathrm{g} /$ $\mathrm{mL}$, respectively, as recorded on $15^{\text {th }}, 15^{\text {th }}$ and $30^{\text {th }}$ day, respectively (Fig. 2).

The PCR amplification of chromosomal DNA of the microalgae with forward and reverse primers revealed efficient amplification. A single band of amplified DNA product of 700 - bp was recorded by gel documentation system. The amplified product fragment was further purified by PCR purification kit (Fermentos, Spain) and sequence generated was published in NCBI databases. The partial sequence of the isolate AT-JP-13 (KP635215) was 99.13\% identical to the consensus sequence of $D$. salina CCAP 19/12 (KJ756842) D. salina KMMCC 1428 (JQ315781) and D. salina UTEX LB 1644 (DQ009765).
De Walne's basal medium is an efficient medium for Dunaliella growth and carotenoid production. However the production medium of organism is varying from one species to another species as well as their native conditions. Since this isolated Dunaliella was different from other reported species, the optimization of environmental and nutritional parameters was required in order to increase the total carotenoid productions. Keeping this in view, a 32 runs Taguchi experimental design was employed to optimize the medium as well to understand the interaction and influence of selected parameters.

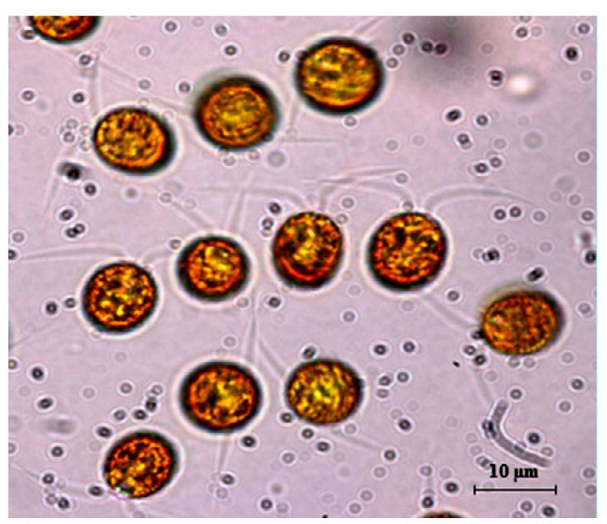

Fig. 1. Accumulation of carotenoids in the cells of $D$. salina (AT-JP-13)

\section{Growth study and pigment estimation of Dunaliella sp. ANCOST -13}

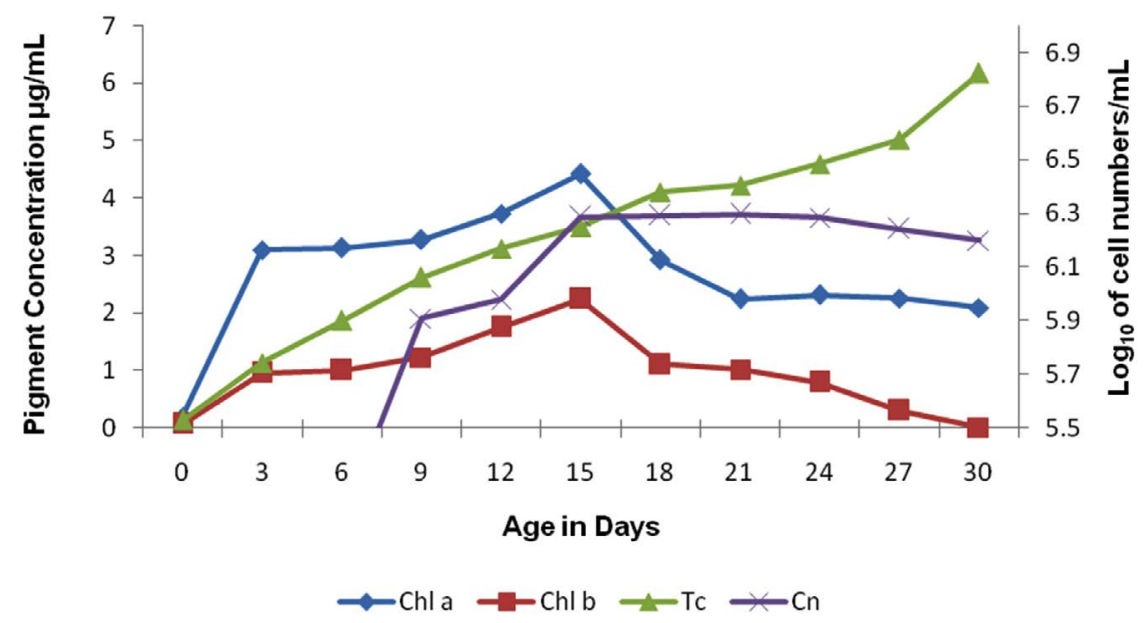

Fig. 2. Growth study and pigment estimation of Dunaliella salina (AT-JP-13). Chl - a: Chlorophyll - a; Chl - b: Chlorophyll - b; Tc: Total carotenoids; Cn: Cell numbers 
Table 1 depicts the 5 selected parameters at 4 different levels. Analysis of data yields the individual as well as interaction effect of selected parameters on total carotenoids production. The experimental data revealed that there is a significant variation in carotenoids production observed along with experimental runs. Minimum and maximum carotenoids production values were observed to be 48 and $232.61 \mu \mathrm{g} / \mathrm{mL}$, respectively, under selected conditions of the medium. The observed variation positively shows the imperative role of optimization on all related factors in achieving the best possible yields.

The average effect of factors at the assigned levels on carotenoids production by Dunaliella salina AT-JP-13 is shown in Fig. 3. At individual level the highest effect on carotenoids production was noticed with light intensity at $3^{\text {rd }}$ level (182.53) followed by concentration of $\mathrm{NaNO}_{3}$ at $2^{\text {nd }}$ level (169.61), $\mathrm{NaCl}$ concentration at $4^{\text {th }}$ level (157.14) and $\mathrm{NaH}_{2} \mathrm{PO}_{4}$ concentration at $1^{\text {st }}$ level (154.84). Among all parameters $\mathrm{pH}$ has the least effect on the carotenoids production at $4^{\text {th }}$ level (153.68). The selected variable preferences are in the following order:

Light intensity $>\mathrm{NaNO}_{3}>\mathrm{NaCl}>\mathrm{NaH}_{2} \mathrm{PO}_{4}>\mathrm{pH}$

In Taguchi method, the interaction between two factors was represented by severity index (SI). Table 2 represents the interaction matrix of various factors, calculated by Qualitek-4 program. Table 2 depicts that interaction between $\mathrm{NaH}_{2} \mathrm{PO}_{4}$ concentration and $\mathrm{pH}$ has highest $\mathrm{SI}$ (76.66 \%) as compared with others. Least SI was observed with interaction between light intensity and $\mathrm{pH}(2.77 \%)$. The light intensity and $\mathrm{NaNO}_{3}$ concentration have a highest individual effect on carotenoids production; however, their interaction has lesser SI (8.37\%).

To determine the influence of each factor on the production of carotenoids by isolated algae, ANOVA approach was used. Factor with interactions are shown in Table 2. Among all selected factors light intensity has the highest contribution (60.59\%) on overall process. After light intensity, a concentration of $\mathrm{NaNO}_{3}$ and $\mathrm{NaH}_{2} \mathrm{PO}_{4}$ has highest effect of 17.89 and $10.33 \%$, respectively. Among all studied parameters, $\mathrm{pH}$ has a least contribution on the carotenoids production. Optimum conditions of selected parameters and their performance in terms of contribution for achieving higher carotenoids yield are shown in table 2 . The optimum conditions predicted by the software are light intensity of $40 \mu \mathrm{Em}^{-1} \mathrm{~s}^{-1}, 0.5 \mathrm{mM} \mathrm{NaH}_{2} \mathrm{PO}_{4}, 1.5 \mathrm{M} \mathrm{NaCl}, 1 \mathrm{mM}$ $\mathrm{NaNO}_{3}$ concentration and $\mathrm{pH}$ of 8 . The predicted carotenoids yield at these optimum conditions is $251.991 \mu \mathrm{g} / \mathrm{mL}$ with total contribution from all the factors being $113.996 \mu \mathrm{g} / \mathrm{mL}$ with grand average

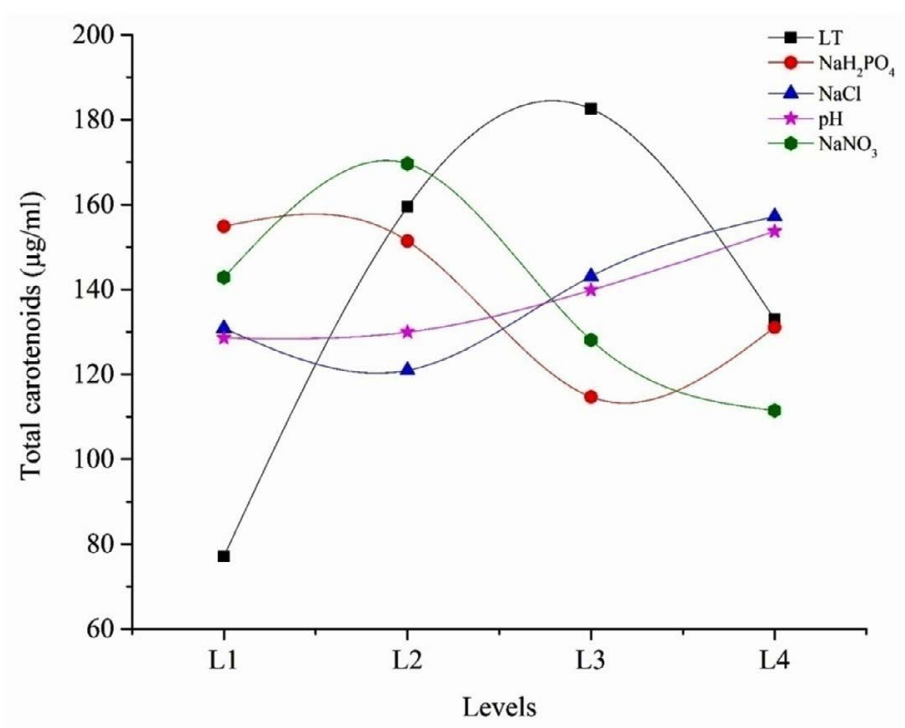

Fig. 3. Influence of the selected parameters at different levels on carotenoids production by isolated algae. (LT = Light intensity) 
performance of $137.995 \mu \mathrm{g} / \mathrm{mL}$. After validating at the predicted conditions, carotenoids production of $249.24 \mu \mathrm{g} / \mathrm{mL}$ was achieved. The obtained yield was nearer to the predicted value, which indicates the robustness of employed design.

Fig. 4 shows the variation reduction achieved with optimized conditions. The sharp curve indicates the improvement on overall carotenoids production by this algal strain. The improved Signal / Noise ratio at optimum condition depicts the reduction in standard deviation before optimization.

The validation data revealed that with the help of L-32 Taguchi experimentation the culture condition were modified. A 4.2 fold (from 48.00 to $249.24 \mu \mathrm{g} / \mathrm{mL}$ ) enhancement in the total carotenoids production was observed with altered culture conditions.

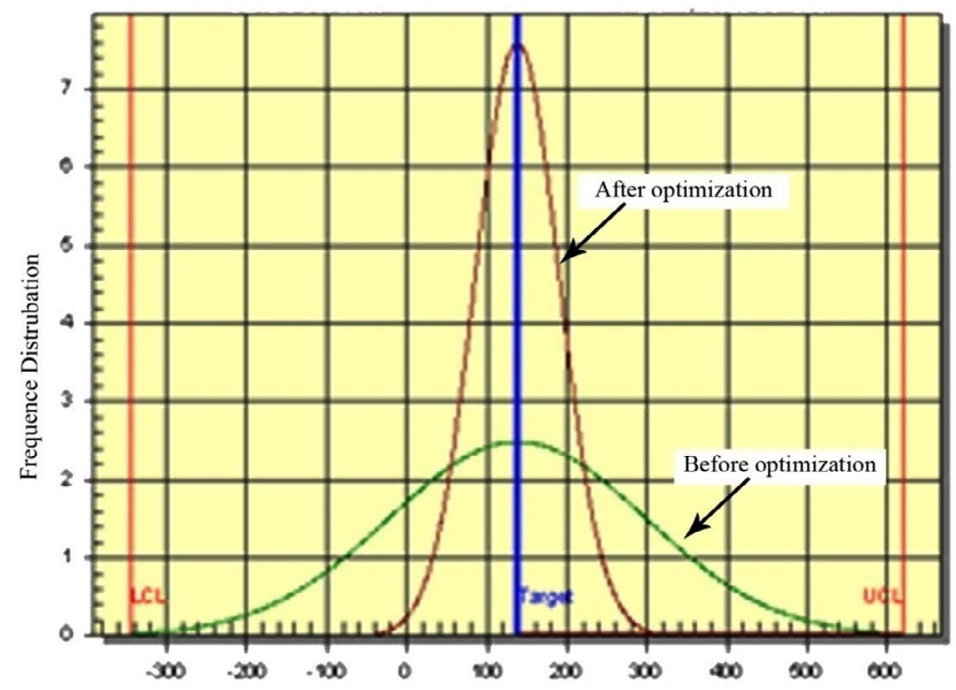

Fig. 4. Variance reduction before and after optimization

\section{DISCUSSION}

Identification of novel species and strains from natural habitats is the primary purpose in the path of obtaining superior productive strains $^{22}$. Hence, in this study, an attempt was made to isolate a superior strain of Dunaliella from seawater. $A \& N$ islands are one of the hot spot of marine biodiversity in the world. Besides, it is not much studied in the context of microalgal and their potentialities because of the wide geographic distribution of saline systems. Marine microorganisms such as bacteria require unique adaptations to survive in these chemically and physically diverse environment leading to extensive species diversity than the terrestrial environment ${ }^{3,23-25}$. Same way, microalgae also tend to have distinctive adaptations characteristics with unique metabolites for survival ${ }^{26}$. It is a challenge to isolate the Dunaliella salina from seawater rather than from the samples of salt pans. Various studies conducted on $D$. Salina so far were mainly collected from hypersaline environments ${ }^{4,27,28}$.

A large volume of seawater was filtered several times and consistent microscopic observations have been made for effective isolation. During initial period of enrichment up to 15 days, the periodical inspection revealed that the Tetraselmis sp. was found to grow in large number than that of Dunaliella and diatoms. Later the growth was started diminishing because of the high salt concentration in the medium which supported the growth of Dunaliella and avoiding Tetraselmis growth. The optimum growth conditions reported earlier for Tetraselmis were: 20-35\% of salinity and temperature ranges from 19 to $21^{\circ} \mathrm{C}^{29}$. Several early studies on the effect of germanium dioxide inhibited the growth of mature Chlorophyta and Phaeophyta species ${ }^{13}$ apart from diatoms; hence the germanium dioxide was taken with limited concentrations in order to prevent the inhibition of target isolate. The present isolate $D$. salina withstands all studied concentrations except 
with minimum inhibition at the higher range $(25 \mu \mathrm{g} / \mathrm{mL})$. After 20 days of enrichment, Dunaliella occurrence was observed because of their slow adaptation to the medium. Some of the species belongs to this Genera has the tendency to adapt to various environmental conditions like salinity, temperature, heavy metals and pesticides ${ }^{30}$. The present results once again proved the nature of its adaptations to extreme environments like A \& $\mathrm{N}$ islands, a rainy tropical climate.

The Present isolate, $D$. salina that has been isolated from seawater in the salinity ranging from 28-30 ppt (0.5 M), also adapted up to 87.66 ppt $(1.5 \mathrm{M}) \mathrm{NaCl}$ concentration. An extensive study made by Borowitzka and Siva ${ }^{30}$ in the taxonomy of this genus revealed that the authors segregated the species $D$. salina based on the optimum salinity range of $>6 \%$. It is contradictory to the results of the present work. However, it is justified by its extreme adaptability to various environments. In addition, some other species was also isolated during isolation task (data not shown) and considered to be euryhaline species. This was well correlated by the study of Oren ${ }^{7}$ citing Lerche ${ }^{31}$ who reported earlier that some of the species of this genus were typically marine organisms and those were never reported in hypersaline environments.

Ambiguity always exists in its identification and physiological characteristics due to its quick adaptation to various environmental conditions and thus the present isolate has its ability to adapt to the different type of environment in $A$ $\& N$ islands ecosystem. Influence of salinity on carotenoid biosynthesis and growth pattern in Dunaliella shows different characters in different media $^{32}$. The different growth patterns exhibited by geographically distinct strains confirm the hypothesis that these algae do not adapt to a specific saline condition, but can tolerate a wide range of salinities ${ }^{33}$.

The isolate obtained from different environments apart from its native environment necessitates the need to study its growth characteristics and carotenoid production. The cells were shown considerable growth up to $24^{\text {th }}$ day and started to decline and remained green in color and were never shown any carotenogenic phase during the growth study and isolation. Cell size was comparatively larger than the other strain mentioned earlier. Pigments, such as Chl-a and Chl-b were dominant up to $15^{\text {th }}$ day, while the total carotenoids were steadily increased up to $30^{\text {th }}$ day of experiment. It clearly indicates that chlorophyll had contributed in its growth, whereas the total carotenoids showed steady increase even at cessation of growth and protected the cell during the nutrient depletion condition ${ }^{5,34}$.

As per previous reports, the alga typically did not show any carotenogenic phase until the present study (Fig. 2). It was also subjected to molecular identification to know up to their species level. Moreover, the taxonomy of Dunaliella, particularly the carotenogenic strains, has a history of controversy as stated by Borowitzka ${ }^{9}$. The author considered that $D$. bardawi ${ }^{35}$ as a nomennudum of $D$. salina Teod, and that $D$. salina was probably of $D$. parva. In the present study, the amplified product size obtained by using universal primer suggests that these primers are well conserved for Dunaliella isolated from the natural habitat. The results acquired in the present study are similar to the observations made by ${ }^{16}$.

Optimization of process and nutrient parameters are essential for enhancing the carotenoids production. Hence L-32 orthogonal array design (Taguchi DOE) was employed. A significant variation of total carotenoid production was observed during experimental runs, indicating the influence of selected parameters and their quantitative requirement for carotenoids production.

Severity Index is a measurement which indicates the percentage of interaction between two factors. Though $\mathrm{pH}$ and $\mathrm{NaH}_{2} \mathrm{PO}_{4}$ concentration have least individual effects, their interaction has a highest significant effect $(\mathrm{SI}=76.66 \%)$ on the carotenoids production. The $\mathrm{pH}$ was noticed in both higher and lower interactions (table 2) indicating that $\mathrm{pH}$ is one of the important factors which affects the carotenoid production either synergistic way along with other parameters. The interaction data reveals that the production of carotenoids by

D. salina, AT-JP-13 depends on the individual as well as the interaction effect of selected parameters.

The analysis of data reveals that light intensity has more contribution (60.59\%) on overall carotenoids production suggesting that 
alteration of light intensity has significant changes in the carotenoids production. Light is the vital factor regulating the rate of synthesis of $\lambda$-carotene in Dunaliella under favorable growth conditions ${ }^{36,37}$. As per the preliminary investigation and in Taguchi experiment the total carotenoid was found to be higher on the $30^{\text {th }}$ day (initial decline phase). This may be due to the high light intensity, lack of cell wall and the cell swelling which accumulate a large amount of carotenoids irrespective of growth. Likewise, the swelling of $D$. salina cells is a typical response to various extreme conditions such as high light intensity and/or low temperature ${ }^{38}$. D. salina cell size has been observed with seven-fold increase in the incident light intensity ${ }^{39}$. Moreover, the high light intensity does not support the cell growth in the present study, instead, it indirectly reflects on the total carotenoids despite its high performance in Taguchi. This is evidently proved the $D$. salina reported to die due to reduced chlorophyll levels under very high-light illumination when it was growing at a slow rate ${ }^{35}$.

Next to light intensity, $\mathrm{NaNO}_{3}$ concentration has shown the highest influence on total carotenoids production. According to Milko $^{40}$, the best source of nitrogen for maximum growth of $D$. salina, $D$. tertiolecta and $D$. viridis was $\mathrm{NaNO}_{3}$. Perhaps the present basal medium also inherently contains the $\mathrm{NaNO}_{3}$. Saha et al. ${ }^{41}$ observed that the best stress conditions include high-light illumination in depleted nitrogen coupled to micronutrients such as $\mathrm{Zn}, \mathrm{Mn}$ and Fe in medium for enhancement of carotenoid production. In addition, Mojaat et al..$^{42}$ observed the accumulation of high quantities of $\beta$-carotene (35 pg/cell) in the nitrate-free culture. These values drastically dropped to 24 and $12 \mathrm{pg} /$ cell at the initial nitrate concentration of 1.2 and $6.0 \mathrm{mM}$, respectively. Usually, nitrate limiting conditions enhance the carotenoid production in the cells, whereas, it is contradictory to the above authors view since the design used in the present study is well correlated with each other. Even at higher concentration, the total carotenoid was increased, while the lower concentration diminishes the carotenoid production, which may be because of other factors used.

The effects of salinity on growth and total carotenoids production by the microalga
D. salina is most important since it was isolated from the normal seawater and not from the hypersaline area. As per the previous reports, $D$. salina had shown the maximum growth at 1 $\mathrm{M} \mathrm{NaCl}$ concentration ${ }^{7}$. Likewise, in the present study also, the organism preferred the lesser range of $\mathrm{NaCl}$ between 0.5 to $1.5 \mathrm{M}$ concentrations. In General, of the various ranges taken the maximum carotenoids accumulated in higher ranges than the lesser ranges. Besides, it was well adapted to all the salinity tested. It is well correlated with the following reports narrated by the various researchers. Salt tolerance and growth experiments showed for their isolate could grow at different salinity levels ranging from 0.5 to 4.0 $\mathrm{M} \mathrm{NaCl}$, thereby elevating the carotenoid content of the cells, which was cultivated at the high salinity of $4 \mathrm{M} \mathrm{NaCl}^{22}$. Fazeli et al. ${ }^{32}$ found that the productivity of total carotenoids on the cellular basis to be very high at extreme salt concentrations (3 $\mathrm{M} \mathrm{NaCl}$ ). D. salina is the widely studied model alga for its incredible ability to acclimatize to a wide range of salinity ${ }^{43}$.

Phosphate is an essential nutrient that plays a vital role in structural and functional components of a living system ${ }^{44}$. Similarly, an investigation was made on the effect of $\mathrm{NaH}_{2} \mathrm{PO}_{4}$. Phosphate also exhibited the same condition but phosphate deprivation had little effect due to intracellular phosphate. In the present study, the phosphate showed less impact on the total carotenoid production by isolated $D$. salina. The concentration of $0.5 \mathrm{mM} \mathrm{NaH}_{2} \mathrm{PO}_{4}$ was found to be optimum for higher carotenoid production. Usually, the optimum phosphate concentration for the growth of $D$. salina and $D$. viridis was 0.002 to $0.025 \mathrm{gL}^{-1}$ of $\mathrm{K}_{2} \mathrm{HPO}_{4}^{40,45}$, while higher concentrations $\left(>5 \mathrm{gL}^{-1}\right)$ inhibited their growth. The ratio of accessory phosphor protective pigments ( $\alpha$ and $\beta$-carotene) to Chlorophyll-a improved under restrictive levels of nitrogen and phosphate ${ }^{46,47}$.

The Taguchi results reveal that $\mathrm{pH}$ has a least contribution on the carotenoid production by isolated $D$. Salina among all studied parameters. However, it gives a tremendous synergetic effect to other parameters to enhance the carotenoids production. Most of the microalgae chose the suitable $\mathrm{pH}$ ranges from 6 to 9 . Keeping this in mind, the present microalga was tested within the range of 7.0 to 8.5 . The alga used in this 
study exhibited normal growth up to $30^{\text {th }}$ day and showed an ample amount of total carotenoids production at the higher $\mathrm{pH}(\mathrm{pH} 8.0)$. The obtained results are contradicting to the report of Ying et $\mathrm{al}^{48}$. The investigators observed that once after 9 days of inoculation, the $\mathrm{pH}$ barely increased and growth was inhibited. This may be prevented in this case by combination of appropriate nutrients supplementation. Shariati ${ }^{49}$ reported that the optimum $\mathrm{pH}$ range for $D$. salina, $D$. pseudosalina and $D$. parva isolated from Iran was between $\mathrm{pH} 7.0$ to 8.0. Thakur et al. ${ }^{50}$ reported that a biologically pure culture of $D$. salina ARL 5 exhibited a wide $\mathrm{pH}$ tolerance within the range of 5-10, a wide temperature tolerance within the range of 18 to $55^{\circ} \mathrm{C}$ and salinity tolerance up to $1 \mathrm{M} \mathrm{KCl}$ concentration.

On the whole, it has been already pointed out that the accumulation of $\beta$-carotene in $D$. salina depends upon the factors, which include high light intensity ${ }^{51,52}$, high salinity ${ }^{53-55}$, extreme temperatures ${ }^{49}$, and deprivation of mineral nutrients like nitrate, phosphate and sulphate ${ }^{34,36,56,57}$. Hence, the present study effectively concludes for the first time that the alga $D$. salina, an extreme salt lover isolated from seawater could be optimized for total carotenoid production by the use of Taguchi tool to know the best synergistic condition of the nutrients available in the medium.

\section{ACKNOWLEDGMENTS}

We are thankful to Dr. M. A. Atmanand, Director, ESSO - National Institute of Ocean Technology (NIOT), for the constant encouragement to conduct this work. We thank Dr. M. Vijayakumaran (Consultant) and Prof. T. Subramoniam, for their critical review of this manuscript. We also thank all the scientific and supporting staffs of ANCOST, ESSO - NIOT, for their invaluable assistance in field and laboratory for completing this research work.

\section{CONFLICT OF INTEREST}

The authors declares that there is no conflict of interest.

\section{AUTHORS' CONTRIBUTION}

$J K R, S T, V N V, D G$ and $K R$ involved in designing the research and experiment. JKR, BB and DPS involved in carrying out the designed experimental procedure. JKR, ST, BB, VNV, DG and $K R$ involved in analysis the data. JKR and $B B$ wrote the manuscript with the input of co-authors. All the authors agreed with the final version of manuscript.

\section{FUNDING}

The authors are thankful for the financial support given by the Earth System Sciences Organization, Ministry of Earth Sciences, Government of India, to carry out this research.

\section{DATA AVAILABILITY}

The datasets are available from the corresponding author on reasonable request.

\section{ETHICS STATEMENT}

Algal sample collection was carried out with a proper approval from the appropriate institutions as per the guidelines of ministry of earth sciences, Government of India.

\section{REFERENCES}

1. Ganesh Kumar A., Baskar B., Santhanakumar J., Vinithkumar N.V., Vijayakumaran M., Kirubagaran R. Diversity and functional properties of intestinal microbial flora of the spiny lobster Panulirus versicolor (Latreille, 1804). J. Mar. Biol. Ass. India, 2010; 52(2): 282-285.

2. Vasanthi L.A., Muruganandam A., Revathi P., Baskar B., Jayapriyan K., Baburajendran R., Munuswamy N. The application of histo-cytopathological biomarkers in the mud crab Scylla serrata (Forskal) to assess heavy metal toxicity in Pulicat Lake, Chennai. Mar. Pollut. Bull., 2014; 81(1): 85-93 https://doi.org/10.1016/j. marpolbul.2014.02.016

3. Balakrishnan B., Sahu B.K., Ranishree J.K., Lourduraj A.V., Nithyanandam M., Packiriswamy N., Panchatcharam P. Assessment of heavy metal concentrations and associated resistant bacterial communities in bulk and rhizosphere soil of Avicennia marina of Pichavaram mangrove, India. Environ. Earth Sci., 2017; 76(1): 58. https://doi.org/10.1007/s12665-016-6378-7

4. Jayappriyan K.R., Rajkumar R., Rengasamy R. Unusual occurrence of non carotenogenic strains of Dunaliella bardawil and Dunaliella parva in India. J. Basic. Microbiol., 2011; 51: 473-483. https://doi. org/10.1002/jobm.201000384

5. Jayappriyan K.R., Rajkumar R., Venkatakrishnan V.S., Nagaraj R., Rengasamy R. In vitro anticancer activity of natural $\lambda$-carotene from Dunaliella salina EU5891199 in PC-3 cells. Biomed. Preventive. Nutria., 2013; 3: 99-105. https://doi.org/10.1016/j.bionut.2012.08.003

6. Dunal F. Extrait dun memoire sur les algues qui colorant en rouge certains eaux des marais selants 
mediterraneens. Ann. Sc. Nat. Bot. Ser., 1838; 9: 172.

7. Oren A. A hundred years of Dunaliella research:1905-2005. Sal. Sys., 2005; 1: 2.

8. Finney K.F., Pomeranz Y., Bruinsma B.L. Use of algae Dunaliella as a protein supplement in bread. Food. Additives., 1984; 61: 402-406.

9. Borowitzka M.A., Borowitzka L.J. Dunaliella. In: Borowitzka M.A., Borowitzka L.J. (Eds.), Microalgal Biotechnology, Cambridge University Press, Cambridge, 1988.

10. Gomez P.I., Barriga A., Cifuentes A.S., Gonzalez M.A. Effect of salinity on the quantity and the quality of carotenoids accumulated by (strain CONC-007) and Dunaliella bardawil (strain ATCC 30861) Chlorophyta. Biol. Res., 2003; 36: 185-192. https://doi.org/10.4067/ S0716-97602003000200008

11. Jha D.K., Vinithkumar N.V., Marimuthu N., Baskar B., Sahu B.K., Das A.K., Kirubagaran R. Field abd GIS based post-tsunami assessment of Scleractinian coral cover in the Aerial Bay group of islands, North Andaman, India. J. Coast. Conserv., 2013; 17: 671-677. https:// doi.org/10.1007/s11852-013-0266-z

12. Orest S., Young A. Low temperature induced synthesis of $\alpha$-carotene in the microalga Dunaliella salina (Chlorophyta). J. Phycol., 1999; 35: 520-527. https:// doi.org/10.1046/j.1529-8817.1999.3530520.x

13. Shea R., Chopin T. Effects of Germanium dioxide, an inhibitor of diatom growth, on the microscopic laboratory cultivation stage of the kelp, Laminaria saccha rina. J. App. Phycol., 2007; 19: 27-32. https:// doi.org/10.1007/s10811-006-9107-x

14. Droop M.R. A procedure for routine purification of algal culture with antibiotics. Br. Phycol. Bull., 1967; 3: 295297. https://doi.org/10.1080/00071616700650171

15. Sambrook K.T., Frisch E.F., Maniatis T. Molecular Cloning: a laboratory manual. Cold Spring Harbor Laboratory, 1989.

16. Rasoul-Amini S., Ghasemi Y., Morowvat M.H., Mohagheghzadeh A. PCR amplification of 18S rRNA, single cell protein production and fatty acid evaluation of some naturally isolated microalgae. Food Chem., 2009; 116: 129-136. https://doi.org/10.1016/j. foodchem.2009.02.025

17. Lichtenthaler H.K. Chlorophylls and carotenoids: pigments of photosynthetic membrances. Meth. Enzymol., 1987; 148: 350-382. https://doi. org/10.1016/0076-6879(87)48036-1

18. Guillard R.R.L. Division rates. In Stein J. (Ed), Handbook of Phycological methods: culture methods and growth measurements. Cambridge University Press, Cambridge, London, 1973.

19. Taguchi G. Quality through engineering design. ; Elsevier Science Publisher, Netherlands, 1993.

20. Prakasham R.S., Sathish T., Brahmaiah P. Biohydrogen production process optimization using anaerobic mixed consortia: A prelude study for use of agro-industrial material hydrolysate as substrate. Biores. Tech., 2010; 101: 5708-5711. https://doi.org/10.1016/j. biortech.2010.01.145

21. Balakrishnan B., Ranishree J.K., Thadikamala S., Panchatcharam P. Purification, characterization and production optimization of a vibriocin produced by mangrove associated Vibrio parahaemolyticus. Asian Pac. J. Trop. Biomed., 2014; 4(4): 253-261. https:// doi.org/10.12980/APJTB.4.2014C947

22. Hejazi M.A., Barzegari A., Gharajeh N.H., Hejazi M.S. Introduction of a novel 18S rDNA gene arrangement along with distinct ITS region in the saline water microalga Dunaliella. Saline Systems, 2010; 6: 1-4. https://doi.org/10.1186/1746-1448-6-4

23. Baskar B., Prabakaran P. Isolation and characterization of copper resistant Exiguo-bacterium strains isolated from rhizosphere soil of Avicennia marina. Res. J. Pharm. Biol. Chem. Sci., 2011; 2(4): 640-646.

24. Baskar B., PrabaKaran B. Characterization of mangrove associated nitrogen fixing halophilic bacterium Panibacillus sp. Int. J. Curr. Res., 2011; 3(9): 065-067.

25. Baskar B., Prabakaran P. Assessment of nitrogen fixing bacterial community present in the rhizosphere of Avicennia marina. Indian J. Geo-Mar. Sci., 2015; 44(3): 318-322

26. Abatzopoulos T.J., Beardmore J.A., Clegg J.S., Sorgeloos P. Artemia: Basic and Applied biology. Kluwer Academic, Dordrecht, 2002. https://doi. org/10.1007/978-94-017-0791-6

27. Borowitzka M.A. High value products from algae, Dunaliella salina and Haematococcus pluvialis. In: Thirakhupt V., Boonakijjinda V. (eds.), Mass Cultures of Microalgae. Proceedings of the Research Seminar and Workshop, Silpakorn University, Thailand. UNESCO: Thailand, 1995.

28. Mishra A., Jha B. Isolation and characterization of extracellular polymeric substances from micro-algae Dunaliella salina under salt stress. Biores. Tech., 2009; 100: 3382-3386. https://doi.org/10.1016/j. biortech.2009.02.006

29. Tawfiq A.S., Al-Musallam L., Al-Shimmari J., Dias P. Optimum production conditions for different highquality marine algae. Hydrobiologia., 1999; 403: 97-107. https://doi.org/10.1023/A:1003725626504

30. Borowitzka M.A., Siva C.J. The taxonomy of the genus Dunaliella (Chlorophyta, Dunaliellales) with emphasis on the marine and halophilic species. J. Appl. Phycol., 2007; 19: 567-590. https://doi.org/10.1007/s10811007-9171-x

31. Lerche W. Untersuchungen ber Entwicklung und Fortpflanzung in der Gattung Dunaliella. Arch. $f$. Protistenkd., 1937; 88: 236-268.

32. Fazeli M.R., Tofighi H., Samadi N., Jamalifar H. Effect of salinity on $\lambda$-carotene production by Dunaliella salina DCCBC26 isolated from the Urmia salt lake, north of Iran. Biores. Tech., 2006; 97: 2453-2456. https://doi. org/10.1016/j.biortech.2005.10.037

33. Garcia F., Freile-Pelegrin Y., Robledo D. Physiological characterization of Dunaliella sp. (Chlorophyta, Volvocales) from Yucatan, Mexico. Biores. Tech., 2007; 98: 1359-1365. https://doi.org/10.1016/j. biortech.2006.05.051

34. Shelly K., Heraud P., Beardall J. Nitrogen limitation in Dunaliella tertiolecta (Chlorophyta) leads to increased susceptibility to damage by UV-B radiation but also increased repair capacity. J. Phycol., 2002; 38: 713-720. https://doi.org/10.1046/j.1529-8817.2002.01147.x

35. Ben-Amotz A., Avron M. Accumulation of metabolites 
by halotolerant algae and its industrial potential. Annu. Rev. Microbial., 1983; 37: 95-119. https://doi. org/10.1146/annurev.mi.37.100183.000523

36. Ben-Amotz A. Effect of irradiance and nutrient deficiency on the chemical composition of Dunaliella bardawil, Ben-Amotz and Avron (Eds) (Volvocales, Chlorophyta). J. Plant. Physiol., 1987; 131: 479-487. https://doi.org/10.1016/S0176-1617(87)80290-0

37. Harding R.W., Shropshire W. Photo control of carotenoid biosynthesis. Annu. Rev. Plant. Physiol., 1980; 31: 217-238. https://doi.org/10.1146/annurev. pp.31.060180.001245

38. Cowan A.K., Rose P.D., Horne L.G. Dunaliella salina: A model system for studying the response of plant cell to stress. J. Exp. Bot., 1992; 43: 1535-1547. https:// doi.org/10.1093/jxb/43.12.1535

39. Lamersa P.P., Janssena M., De Vos R.C., Bino R.J., Wijffels R.H. Carotenoid and fatty acid metabolism in nitrogen-starved Dunaliella salina, a unicellular green microalga. J. Biotech., 2012; 162: 21-27. https://doi. org/10.1016/j.jbiotec.2012.04.018

40. Milko E.S. The effect of various environmental factors upon pigment formation in the alga Dunaliella salina. Mikrobiologiya, 1963; 32: 299-307.

41. Saha S.K., Moane S., Murray P. Effect of macro- and micro-nutrient limitation on superoxide dismutase activities and carotenoid levels in microalga Dunaliella salina CCAP 19/18. Biores. Tech., 2013; 14: 723-28. https://doi.org/10.1016/j.biortech.2013.08.022

42. Mojaat M., Foucault A., Pruvost J., Legrand J. Effect of organic carbon sources and $\mathrm{Fe}^{2+}$ ions on growth and $\lambda$-carotene accumulation by Dunaliella salina. Biochem. Eng. J., 2008; 39: 177-184. https://doi.org/10.1016/j. bej.2007.09.009

43. Giordano M., Pezzoni V., Hell R. Strategies for the allocation of resources under sulfur limitation in the green alga Dunaliella salina. Plant Physiol., 2000; 124: 857-886. https://doi.org/10.1104/pp.124.2.857

44. Daram P., Brunner S., Persson B.L., Amrhein N., Buche $M$. Functional analysis and cell-specific expression of a phosphate transporter from tomato. Planta., 1998; 206: 225-233. https://doi.org/10.1104/pp.124.2.857

45. Giobor A. The culture of brine algae. Biological Bulletin Woods Hole., 1956; 3: 223-229. https://doi. org/10.2307/1539013

46. Krom M.D., Brenner S. Phosphorus limitation of primary productivity in the eastern Mediterranean Sea. Limnol. Oceanogr., 1991; 37: 424-432. https:// doi.org/10.4319/lo.1991.36.3.0424
47. Geider R.J., Macintry H.L., Graziano L.M., Mckay R.M. Responses of the photosynthesis apparatus of Dunaliella tertiolecta (Chlorophyceae) to nitrogen and phosphorous limitations. Eur. J. Phycol., 1998; 33: 315-332. https://doi.org/10.1080/096702698100017 36813

48. Ying K., Gilmour D.J., Shi Y., Zimmerman W.B. Growth Enhancement of Dunaliella salina by Microbubble Induced Airlift Loop Bioreactor (ALB)-The Relation between Mass Transfer and Growth Rate. J. Biomat. Nanobio., 2013; 4: 1-9. https://doi.org/10.4236/ jbnb.2013.42A001

49. Shariati M. Characterization of three species of Dunaliella salina, Dunaliella parva and Dunaliella pseudosalina isolated from salt marshes of Gave Khoni Isfahan-Iran. Iranian J. Sci. Technol., 2003; 27: 185-190.

50. Thakur A., Kumar H.D., Cowsik S.M. Effect of pH and inorganic carbon concentration on growth, glycerol production, photosynthesis and dark respiration of Dunaliella salina. Cytobios., 2000; 102: 69-74.

51. Massyuk N.P., Radchenko M.I. Comparative chromatographic study of the pigments in some species and strains of Dunaliella. Hydrobiologia., 1970; 6: 51-58.

52. Semenenko V.E., Abdullayev A.A. Parametric control of $\lambda$-carotene in Dunaliella salina cells under conditions of intensive cultivation. Sov. Plant Physiol., 1980; 27: 22-30.

53. Evans R.W., Kates M., Ginzburg M., Ginzburg B.Z. Lipid composition of halotolerant algae Dunaliella parva Lerche and Dunaliella tertiolecta. Biochim. Biophys. Acta., 1982; 712: 186-195. https://doi. org/10.1016/0005-2760(82)90101-1

54. Mortain-Bernard A., Rey P., ElArmani A.E., Lament A. Pyrophosphate inorganique et synthese de carotene Dunaliella salina. Life Sci., 1994; 317: 485-488.

55. Henley W.J., Major K.M., Hironaka J.L. Responses to salinity and heat stress in two halotolerant Chlorophyte algae. J. Phycol., 2002; 38: 757-766. https://doi.org/10.1046/j.1529-8817.2002.01172.x

56. Borowitzka L.J., Borowitzka M.A. Industrial production methods and Economics. In Cresswell R.C., Rees T.A.V., Shah N. (Eds.), Algal and Cyanobacterial biotechnology. Longmann Scientific, London, 1989.

57. Vorst P., Barrd R.L., Mor L.R., Korthals H.J., Van D. Effect of growth arrest on carotene accumulation photosynthesis in Dunaliella. Microbiol., 1994; 140: 1411-1417. https://doi.org/10.1099/00221287-1406-1411 